\title{
THE USE OF MULTIMEDIA AS A DISTRACTION TO REDUCE ANXIETY REACTION AMONG PAEDIATRIC PATIENTS DURING CAST REMOVAL AT HOSPITAL TENGKU AMPUAN AFZAN
}

Tengku Kashfil ${ }^{1}$

${ }^{1}$ Kulliyah Of Medicine, International Islamic University Malaysia.

Presenter: Tengku Kashfil, kashfil_84@hotmail.com

Introduction: Cast removal procedures can be a daunting experience for children giving rise to anxiety. The objective of this study is to measure the level of anxiety in children during cast removal at Hospital Tengku Ampuan Afzan.

Materials and method: An experimental study was conducted with a sample of 40 paediatric patients with upper limb fractures and cast removal were randomly assigned into two groups: with multimedia distraction or without (control). Patient's heart rate was measured using a pulse oximeter before, during and after cast removal.

Results: A total number of 20 children were randomized to multimedia distraction and another 20 to control with no distractions. The mean rise in heart rate between preprocedure and during procedure 5.3 beats/min in multimedia distraction group and 16.35 beats $/ \mathrm{min}$ in control group $(P=0.001)$. The mean difference in heart rate between the pre-procedure and during the procedure was 5.64 beats $/ \mathrm{min}$ in the multimedia distraction group and 13.13 beats/ $\mathrm{min}$ in the control group $(P=0.05)$.

Conclusion: There was significant decrease in heart rate during cast removal with multimedia distraction. Therefore multimedia distraction is a useful tool in reducing anxiety among children during cast removal. 